
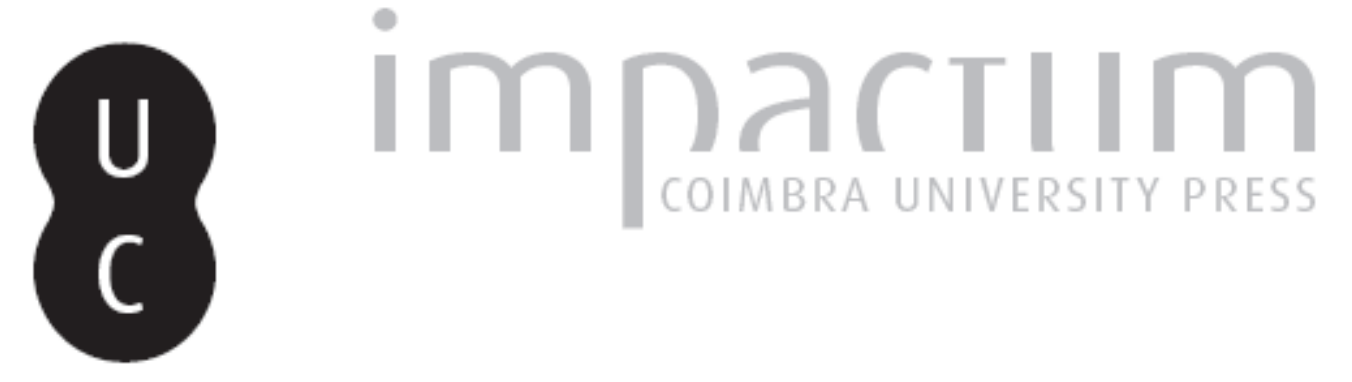

\title{
Datação pelo radiocarbono de um cepo de âncora em chumbo encontrado na Berlenga
}

Autor(es): $\quad$ Cabral, J. M. Peixoto; Meireles, J M.; Soares, A. M. Monge; Veríssimo, L.

Publicado por: Imprensa da Universidade de Coimbra

URL persistente:

URI:http://hdl.handle.net/10316.2/45545

DOI:

DOI:https://dx.doi.org/10.14195/1647-8657_29_3

Accessed : $\quad$ 26-Apr-2023 12:04:08

A navegação consulta e descarregamento dos títulos inseridos nas Bibliotecas Digitais UC Digitalis, UC Pombalina e UC Impactum, pressupõem a aceitação plena e sem reservas dos Termos e Condições de Uso destas Bibliotecas Digitais, disponíveis em https://digitalis.uc.pt/pt-pt/termos.

Conforme exposto nos referidos Termos e Condições de Uso, o descarregamento de títulos de acesso restrito requer uma licença válida de autorização devendo o utilizador aceder ao(s) documento(s) a partir de um endereço de IP da instituição detentora da supramencionada licença.

Ao utilizador é apenas permitido o descarregamento para uso pessoal, pelo que o emprego do(s) título(s) descarregado(s) para outro fim, designadamente comercial, carece de autorização do respetivo autor ou editor da obra.

Na medida em que todas as obras da UC Digitalis se encontram protegidas pelo Código do Direito de Autor e Direitos Conexos e demais legislação aplicável, toda a cópia, parcial ou total, deste documento, nos casos em que é legalmente admitida, deverá conter ou fazer-se acompanhar por este aviso.

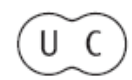


FACULDADE DE LETRAS

INSTITUTO DE ARQUEOLOGIA

CONIMBRIGA

VOLUME XXIX

UNIVERSIDADE DE COIMBRA

1990 
J. M. Peixoto Cabral*, J M. Meireles**, A. M. Monge Soares* e L.

VERÍSSIMO**

DAT AÇÃO PELO RADIOCARBONO DE UM CEPO DE ÂNCORA EM CHUMBO ENCONTRADO NA BERLENGA

«Conimbriga», XXIX, 1990, 59-68

RESUMO: Procedeu-se à datação de um cepo de âncora em chumbo, com alma em madeira de aderno (Phillyrea latifolia L.), encontrado próximo da ilha Berlenga. Obtiveram-se as datas convencionais de radiocarbono ICEN-479 $2370+80$ BP e ICEN-630 2320+50 BP, cuja média ponderada é de $2330+45$ BP. A data calibrada aponta para que o cepo seja datável dos finais do séc. V a. C. ou do início do séc. IV a. C., isto é, que seja proveniente de um navio presumivelmente púnico. Este resultado põe em causa a prática corrente de atribuir à Época Romana todos os cepos de chumbo encontrados na fachada atlântica da Península Ibérica.

SUMMARY: Radiocarbon dating of a leaden anchor stock with a wooden bar found at Berlenga Island, near Peniche (Portugal), yielded $2330+45$ BP. Calibration of this date indicates that the stock must have been originated from a Punic vessel dated to the end of the fifht or the beginning of the fourth century B. C. and it puts in question the attribution currently made to the Roman period of all stocks found at the seabed off the Portuguese coast.

* Departamento de Química, ICEN (LNETI), 2685 Sacavém.

** Museu Municipal de Peniche, 2520 Peniche. 
(Página deixada propositadamente em branco) 


\section{DATAÇÃO PELO RADIOCARBONO \\ DE UM CEPO DE ÂNCORA EM CHUMBO ENCONTRADO NA BERLENGA}

Em 1983, um de nós (L. V.), quando procedia a um mergulho na zona da Berlenga, descobriu um cepo de âncora em chumbo de dimensões excepcionais. Cerca de um ano depois, com o apoio do Museu do Mar de Cascais, procedeu-se à sua recuperação, tendo o cepo ficado depositado no Museu Municipal de Peniche.

Entretanto outros cepos foram detectados no mesmo local e alguns deles recuperados. Entre os localizados, mas que ainda permanecem no fundo do mar, destaca-se um de grandes dimensões $(2,65 \mathrm{~m})$, presumindo-se que tenha também a alma em madeira. É interessante nota' que as zonas da Berlenga e do Cabo Espichei são aquelas onde tem sido recuperada a maior parte dos cepos de âncora em chumbo encontrados até agora em águas portuguesas.

O cepo em questão (Fig. 1), embora meça $2,55 \mathrm{~m}$ de comprimento, pesa somente $423 \mathrm{~kg}$, devido à existência de uma alma em madeira. Parte desta madeira conservou-se no interior do cepo, o que permitiu a colheita de amostras para a sua identificação e datação pelo radiocarbono.

A presente nota tem por objectivo dar a conhecer os resultados obtidos com esta datação e zpresentar algumas considerações sobre a sua interpretação.

\section{Metodologia utilizada e resultados obtidos}

Com o auxílio de um formão, retirou-se uma amostra de madeira com o peso de cerca de $50 \mathrm{~g}$, aproveitando uma abertura irregular existente numa das faces do cepo criada pela corrosão sofrida pelo chumbo enquanto o cepo permaneceu no fundo do mar. Alguns fragmentos 
desta amostra destinaram-se à identificação da madeira (ver Apêndice); os restantes foram utilizados para fazer a sua datação pelo radiocarbono.

Os fragmentos seleccionados para a datação foram reduzidos a pequenas aparas, e estas foram tratadas com uma solução aquosa de hidróxido de sódio, lavadas depois em água destilada até $\mathrm{pH}$ neutro e, em seguida, atacadas com uma solução aquosa de ácido nítrico $6 \mathrm{~N}$, de modo a obter-se uma nitrocelulose. Este tratamento é bastante severo a diminuição do peso da amostra, após o tratamento, é apreciável - mas muito efectivo na remoção de eventuais contaminantes. A nitrocelulose foi finalmente queimada numa atmosfera de oxigénio, a $5 \mathrm{~atm}$, obtendo-se dióxido de carbono, a partir do qual foi sintetizado benzeno (SOARES e CABRAL, 1986; SOARES, 1989). Este benzeno foi deixado mais de um mês no congelador de um frigorífico, a fim de garantir que qualquer ${ }^{222} \mathrm{Rn}$ que pudesse conter decaísse para valores desprezáveis. Passado esse tempo, mediu-se a actividade específica do ${ }^{14} \mathrm{C}$ contido no benzeno, por intermédio de um detector de cintilação líquida, a qual conduziu à seguinte data convencional de radiocarbono:

\section{ICEN-479 237Of80 BP $\boldsymbol{8}^{u} \mathrm{C}=-\mathbf{2 4}, \mathbf{1 7 \%} \%$}

Fazendo a sua calibração, mediante a curva de STUIVER e PEARSON (1986), obtém-se a intercepção em 403 cal AC e os seguintes intervalos:

para um grau de confiança de $68,3 \%$ (1 sigma):

752 - $708 \mathrm{cal} \mathrm{AC,} 531$ - $390 \mathrm{cal} \mathrm{AC}$;

para um grau de confiança de $95,5 \%$ ( 2 sigma):

780-360 cal AC, 290-251 cal AC.

Importa notar que todos os cepos de âncora em chumbo até agora descobertos na costa portuguesa têm sido atribuídos à Época Romana (MAIA, 1975; EDMONDSON, 1987). Assim, o resultado obtido não corresponde ao esperado. Achou-se, por isso, que seria de toda a conveniência realizar uma segunda datação da madeira da alma do cepo.

Procedeu-se, então, à colheita de uma nova amostra, com cerca de $100 \mathrm{~g}$ de peso, a qual foi sujeita a um tratamento de descontaminação mais severo que o utilizado para a primeira. Neste caso, em vez de ácido nítrico, usou-se hipoclorito de sódio a $8 \%$ (percentagem de cloro activo), de modo a obter também uma celulose. O procedimento utilizado para fazer a sua datação foi, depois, em tudo idêntico ao descrito anteriormente. 
A data convencional de radiocarbono determinada nesta segunda datação foi a seguinte:

$$
\text { ICEN }-630 \quad 2320+50 \mathrm{BP} \quad \hat{o}^{u} \mathrm{C}=-25,59^{\circ} / \ll,
$$

Note-se que a diferença existente entre as duas datas convencionais de radiocarbono atrás referidas é de $50+90$ anos, o que significa que, do ponto de vista estatístico, não são diferenciáveis. Deste modo, e tendo em atenção que elas foram obtidas a partir de duas amostras colhidas independentemente do mesmo troço de madeira, é legítimo fazer a sua média ponderada (WARD e WILSON, 1978). Esta média é de $2330+45$ BP a qual, calibrada pela curva de STUIVER e PEARSON (1986), tem a intercepção em 397 cal AC e corresponde aos seguintes intervalos:

para 1 sigma: 404 - 389 cal AC;

para 2 sigma: 511 - 432 cal AC, 429 - 369 cal AC, 271 - 269 cal AC.

\section{Discussão}

Os resultados alcançados permitem concluir que o arbusto ou árvore que forneceu a madeira para a alma do cepo, recuperado na Berlenga, terá crescido alguns séculos antes da ocupação romana da Península Ibérica. Assim, duas hipóteses se poderão considerar ao atribuir uma data para o cepo: a) o cepo ser romano, caso a madeira nele existente tenha sido reutilizada; b) o cepo não ser romano mas sim proveniente de um barco, porventura púnico, dos finais do séc. $\mathrm{V}$ ou dos princípios do séc. IV a. C. (a probalidade de a verdadeira idade da madeira se encontrar em qualquer dos dois intervalos determinados para o grau de confiança de $95,5 \%$ é diminuta - ver STUIVER e REIMER, 1987).

Julgamos que a primeira hipótese é pouco provável, uma vez que, na Europa mediterrânica, as madeiras têm, quando não protegidas, uma sobrevivência curta, dada a sua rápida degradação quando expostas ao meio ambiente.

A segunda hipótese julgamo-la, pelo contrário, aceitável na medida em que dados arqueológicos, quer em Portugal quer na bacia do Mediterrâneo, não invalidam, antes tomam plausível, como veremos seguidamente, a atribuição de uma data recuada ao cepo de âncora. 
A análise da madeira do cepo permitiu concluir que se trata de aderno (Phillyrea latifolia L.), "um arbusto ou uma pequena árvore sempre verde constituinte das matas e matagais esclerófilos de características mediterrânicas" (ver Apêndice). Se uma origem para esta madeira no território actualmente português não é invalidada pela identificação efectuada, a sua atribuição, no entanto, poderá também ser conferida, e talvez com maior probabilidade, à região circum-mediterrânica. É no Mediterrâneo que tem sido encontrada a maior parte dos cepos de chumbo até hoje recuperados, diminuindo a frequência dos achados à medida que nos afastamos dessa região, o que, conjuntamente com o estudo dos contextos onde têm aparecido e as descrições das fontes históricas, aponta claramente para uma origem mediterrânica (MERCANTI, 1979).

Investigações realizadas nessa região mostraram que âncoras de madeira, com o cepo em chumbo, foram usadas desde o séc. VII a. C. até ao séc. III-IV d. C, (Mercanti, 1979; KULEFF et al, 1991). O cepo de âncora em apreço poderá incluir-se no tipo $3 d$ de Kapitan, caracterizado por (KAPITÄN, 1984, p. 38): "stocks with a wooden cross-bar in the box instead of a leaden one. In the hole made through the shank a wooden peg sufficiently protruding at both sides was inserted before casting. (...) The exterior of the box of this type of stock being at first rectangular (1) was then rounded off assuming a more or less oval design (2) which was less of an obstruction than the angular box". Note-se que o cepo da Berlenga poderá incluir-se na variante 1 , a mais primitiva do tipo $3 d$. Repare-se, por outro lado, que este cepo poderá corresponder tipologicamente à transição entre o tipo $3 c$ (totalmente em chumbo, com uma barra moldada do mesmo metal a atravessar o orifício central do cepo) e o tipo $3 d$, dado que nele coexistem a barra em chumbo e a alma em madeira. Tudo leva a crer, portanto, que se trate da variante mais primitiva do tipo $3 d$.

Dois cepos de âncora em chumbo com alma em madeira já foram datados pelo radiocarbono. Um proveniente de Avola (Siracusa) foi datado em 1950TBP - R-718 - (ALESSIO et al, 1973) e outro, também proveniente da região de Siracusa, em 2030+100 BP - B-2213 (KAPITÄN, 1978). Três outros cepos de âncora achados em Antheor, provenientes do naufrágio "Chrétienne C", foram datados pelo contexto na segunda metade do séc. II a. C. (KAPITÄN, 1978, p. 271).

Note-se, além disso, que, segundo KAPITÄn (1978, nota 3), nos cepos de âncora em chumbo com alma em madeira não existem relevos 
figurativos ou inscritos nas faces, ao contrário do que acontece com os cepos totalmente em chumbo da Época Romana ou Helenística tardia. Este investigador sugeriu a hipótese de que isso poderá ser devido "to the circumstance that they were produced by people with different ideological conceptions".

Resumindo, se compararmos o cepo da Berlenga com os provenientes do Mediterrâneo, poderá inferir-se que, no seu tipo, constitui uma variante primitiva, possivelmente anterior à segunda metade do séc. II a. C, caso a evolução tipológica atrás descrita tenha significado cronológico, e que, aceitando a sugestão de Kapitän, foi produzido, tal como os seus congéneres mediterrânicos, por gente com concepções ideológicas diferentes das dos Romanos.

Os dados arqueológicos na fachada atlântica da Península Ibérica apontam para um relacionamento marítimo entre o Mediterrâneo e o Atlântico desde os inícios do séc. VII a. C., primeiramente de origem fenícia e, depois da batalha de Alalia (535 a. C), de origem púnica (SILVA, 1990; Correia, 1990). A estação arqueológica de Santa Olaia (ROCHA, 1971), na vizinhança da Figueira da Foz e a norte da Berlenga, é bem ilustrativa desse relacionamento.

A hipótese que tínhamos considerado de atribuir o cepo de âncora da Berlenga a um barco púnico parece-nos, pois, bastante plausível, constituindo tal testemunho arqueológico a primeira evidência directa de navios púnicos na costa atlântica da Península Ibérica. Ele põe em causa a atribuição correntemente feita à Época Romana de todos os cepos em chumbo encontrados na costa portuguesa, atribuição essa que, possivelmente, terá de ser revista nalguns casos.

\section{Agradecimentos}

Agradece-se reconhecidamente: ao Museu Nacional de Arqueologia o obséquio da cedência do desenho do cepo; ao arqueólogo Jean Yves Blot, colaborador do Museu Municipal de Peniche, que chamou a atenção para a importância em datar o cepo pelo radiocarbono; e à Câmara Municipal de Peniche, que custeou as despesas desta datação e que tem dado um total apoio à equipa do Museu Municipal nas várias tarefas relacionadas com a recuperação e valorização dos testemunhos arqueológicos recuperados na Berlenga. 


\section{BIBLIOGRAFIA}

Alessio, M., Bella, F.; Improta, S,; Belluomini, G.; Calderoni, G.; Cortesi, C; TURI, B., 1973- University of Rome Carbon-14 Dates X. "Radiocarbon", 15 (1), pp. 165-178.

CORREIA, V. H., 1990 - A Expansão Orientalizante na Fachada Atlântica Peninsular. Dados conhecidos e perspectivas, "Trabalhos de Antropologia e Etnologia", 30, pp. 177-192.

EDMONDSON, J. C, 1987- Two Industries in Lusitania - Mining and Garum Production. BAR International Series, 362. Oxford.

KAPITÄN, G., 1978 - Exploration at Cape Graziano, Filicudi, Aeolian Islands, 1977, Results with annotations on the typology of ancient anchors. IJNA, 7 (4), pp. 269-277.

KAPITÄN, G., 1984 - Ancient anchors - technology and classification. IJNA, 13 (1), pp. 33-44.

KULEFF, I.; DJINGOVA, R.; ALEXANDROVA, A.; ANGELOVA, C, 1991-INAA and A AS of ancient lead anchors found along the Bulgarian Black Sea Coast. “Archaeometry 90", (Eds. E. PERNICKA e G. A. WAGNER), Birkhatiser, Basel, pp. 199-208.

MAI A, M., 1975 - Cepos de chumbo de âncoras romanas encontradas ao largo de Sesimbra. "Setúbal Arqueológica", voi. I, pp. 177-180.

MERCANTI, M. P., 1979 - Ancorae Antiquae. Per una cronologia preliminare delle ancore del Mediterraneo. "Studia Archeologica", 20, Roma.

ROCHA, A. S., 1971 - Memórias e Explorações Arqueológicas. Voi. II. Estações pré-romanas da Idade do Ferro nas vizinhanças da Figueira. Acta Universitatis Conimbrigensis, Coimbra.

SILVA, A. C. F., 1990 - A Idade do Ferro em Portugal, in Portugal: das Origens à Romanização, (Coord. J. ALARCÃO), Editorial Presença, Lisboa, pp. 259-341.

SOARES, A. M., 1989 - O efeito de Reservatório Oceânico nas Aguas Costeiras de Portugal Continental. Departamento de Química, ICEN-LNETI, $135 \mathrm{p}$.

SOARES, A. M.; CABRAL, J. M. P., 1986 - Datação pelo Radiocarbono. O Laboratório de Radiocarbono do LNETI. "Informação Arqueológica", 7, pp. 211-213.

STUIVER, M.; PEARSON, G. W., 1986 High-Precision Calibration of the Radiocarbon Time Scale, AD 1950-500 BC. "Radiocarbon", 28 (2B), pp. 805-838.

STUIVER, M.; REIMER, P. J., 1987 - Radiocarbon Calibration Program (CALIB). Rev. 2.0.

WARD, G. K.; WILSON, S. R., 1978 - Procedures for comparing and combining radiocarbon age determinations: a critique. "Archaeometry" 20 (1), pp. 19-31. 


\title{
APÊNDICE \\ IDENTIFICAÇÃO DE UM FRAGMENTO DE MADEIRA DO CEPO DE ÂNCORA DA BERLENGA
}

\author{
por PAULA FERNANDES QUEIROZ*
}

\section{Descrição das características morfológicas:}

Anéis de crescimento: bem distintos. Porosidade difusa. Vasos dispostos em bandas tangenciais, bifurcadas.

Vasos: reunido\$ em grupos de orientação tangencial. Circulares e elípticos em secção transversal. Diâmetro máximo de 50 um. Perfurações simples. Espessamentos espiralados presentes principalmente nos vasos de menor diâmetro.

Pontuações intervasculares: pontuações areoladas, circulares, com um diâmetro de 4 a 5 /xm, dispostas em fiadas longitudinais.

Pontuações radio-vasculares: pontuações alternas, de abertura circular, com 2, 5 a 3 jum de diâmetro.

Pontuações para as fibras: idênticas às pontuações intervasculares.

Parênquima: paratraqueal e apotraqueal disperso, pouco abundante.

Fibras: fibras liberiformes de parede muito espessa. Fibrotraqueídos vasicêntricos, numerosos, com espessamentos espiralados.

Raios: raios unisseriados abundantes, com 4 a 10 células de altura, formados por células quadrangulares. Raios multisseriados com 2 a 3 células de largura, fracamente heterogéneos com uma (mais raramente duas) fiada de células quadrangulares no topo e na base do raio e células prostradas na parte central.

\footnotetext{
* Laboratório de Paleoecologia, Museu Nacional de Arqueologia, 1400 Lisboa.
} 
Identificação:

Com base nas características anatómicas observadas e na comparação com material da colecção de referência do Museu Nacional de Arqueologia e Etnologia, a amostra analisada foi identificada como um fragmento de madeira de Phillyrea latifolia L. (Aderno).

\section{Comentários:}

A Phillyrea latifolia é um arbusto ou uma pequena árvore sempre verde constituinte das matas e matagais esclerófilos de características mediterrânicas. Associada quer às matas de Quercus faginea (carvalho português) e a matagais da sua série de sucessão, quer às formações litorais mais xéricas, é certamente um importante elemento da vegetação natural $\mathrm{d}^{\circ}$ toda a faixa litoral Centro-Sul do País. Segundo Albino de Carvalho, (CArvalho, 1956 - Madeira de Folhosas. "Boi. Soc. Port. Ciências Naturais", 2. a série, 5 (2), 54-260) a madeira de Phillyrea latifolia é dura, pesada e resistente, sendo geralmente utilizada em pequenos trabalhos de torno e escultura. A possibilidade da sua utilização em peças de maiores dimensões está hoje em dia condicionada pela raridade de indivíduos de elevado porte arbóreo. 


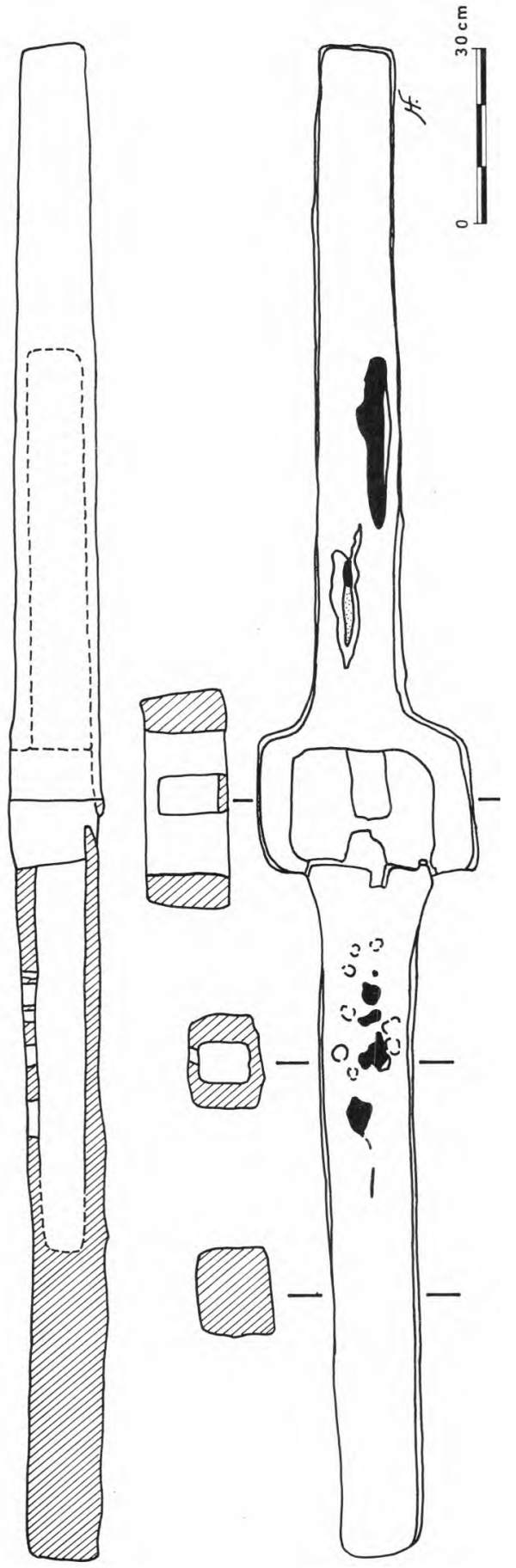

FIG. 1. Cepo de âncora da Berlenga 